\title{
Approximate fixed points of generalized convex contractions
}

\author{
Mehdi Amir Miandaragh ${ }^{1}$, Mihai Postolache $2^{2^{*}}$ and Shahram Rezapour ${ }^{1}$
}

"Correspondence: emscolar@yahoo.com

${ }^{2}$ Department of Mathematics, University Politehnica of Bucharest, 313 Splaiul Independenţei, Bucharest, 060042, Romania Full list of author information is available at the end of the article

\begin{abstract}
In this paper, we introduce the concept of generalized convex contractions and give some results about approximate fixed points of the contractions on metric spaces. By providing some examples, we show that our results are real generalization of the main results of Ghorbanian et al. (Comput. Math. Appl. 63:1361-1368, 2012) and Istratescu (I. Ann. Mat. Pura Appl. 130(4):89-104, 1982).
\end{abstract}

\section{Introduction}

Istratescu [1] introduced the notion of convex contraction. He proved that each convex contraction has a unique fixed point on a complete metric space, see also [2]. Recently Ghorbanian, Rezapour and Shahzad generalized his results to complete ordered metric spaces, [3]. In recent years, there have appeared some works on approximate fixed point results (see, for example, [4-8] and the references therein). In this paper, by considering the key work [9] and using the main idea of [10], we introduce the concept of generalized convex contractions and generalize the main results of [3] and [1].

\section{Preliminaries}

Let $(X, d)$ be a metric space, $T$ be a selfmap on $X$ and $\alpha: X \times X \rightarrow[0, \infty)$ be a mapping.

In accordance with [10], we say that $T$ is $\alpha$-admissible whenever $\alpha(x, y) \geq 1$ implies $\alpha(T x, T y) \geq 1$. Also, we say that $X$ has the property $(\mathrm{H})$ whenever for each $x, y \in X$, there exists $z \in X$ such that $\alpha(x, z) \geq 1$ and $\alpha(y, z) \geq 1$; also see [11].

The selfmap $T$ on $X$ is called a generalized convex contraction whenever there exist a mapping $\alpha: X \times X \rightarrow[0, \infty)$ and $a, b \in[0,1)$, with $a+b<1$, such that

$$
\alpha(x, y) d\left(T^{2} x, T^{2} y\right) \leq a d(T x, T y)+b d(x, y)
$$

for all $x, y \in X$.

We say that $\alpha$ is the based mapping. Also, we say that the selfmap $T$ on $X$ is a generalized convex contraction of order 2 whenever there exist a mapping $\alpha: X \times X \rightarrow[0, \infty)$ and $a_{1}, a_{2}, b_{1}, b_{2} \in[0,1)$ with $a_{1}+a_{2}+b_{1}+b_{2}<1$ such that

$$
\alpha(x, y) d\left(T^{2} x, T^{2} y\right) \leq a_{1} d(x, T x)+a_{2} d\left(T x, T^{2} x\right)+b_{1} d(y, T y)+b_{2} d\left(T y, T^{2} y\right)
$$

for all $x, y \in X$. Other useful references: [12-15].

\section{Springer}

@2013 Miandaragh et al.; licensee Springer. This is an Open Access article distributed under the terms of the Creative Commons Attribution License (http://creativecommons.org/licenses/by/2.0), which permits unrestricted use, distribution, and reproduction in any medium, provided the original work is properly cited. 
Let $\varepsilon>0$ be given. $x_{0} \in X$ is an $\varepsilon$-fixed point of the selfmap $T$ on $X$ whenever $d\left(x_{0}, T x_{0}\right)<$ $\varepsilon$, see [16]. Denote the set of all $\varepsilon$-fixed points of $T$ by $F_{\varepsilon}(T)$. We say that $T$ has an approximate fixed point (or $T$ has the approximate fixed point property) whenever $T$ has an $\varepsilon$-fixed point for all $\varepsilon>0$, see [17]. It is known that there are selfmaps which have approximate fixed points while have no fixed points.

We need the following result in our main results.

Lemma $2.1([18])$ Let $(X, d)$ be a metric space and $T$ be an asymptotic regular selfmap on $X$, that is, $d\left(T^{n}(x), T^{n+1}(x)\right) \rightarrow 0$ for all $x \in X$. Then $T$ has the approximate fixed point property.

\section{The main results}

Now, we are ready to state and prove our main results.

Theorem 3.1 Let $(X, d)$ be a metric space and $T$ be a generalized convex contraction on $X$ with the based mapping $\alpha$. Suppose that $T$ is $\alpha$-admissible and there exists $x_{0} \in X$ such that $\alpha\left(x_{0}, T x_{0}\right) \geq 1$.

Then $T$ has an approximate fixed point.

Moreover, $T$ has a fixed point whenever $T$ is continuous and $(X, d)$ is a complete metric space, and also $T$ has a unique fixed point whenever $X$ has the property $(\mathrm{H})$.

Proof Let $x_{0} \in X$ be such that $\alpha\left(x_{0}, T x_{0}\right) \geq 1$. Define the sequence $\left\{x_{n}\right\}$ by $x_{n+1}=T^{n+1} x_{0}$ for all $n \geq 0$.

If $x_{n}=x_{n+1}$ for some $n$, then we have nothing to prove.

Assume that $x_{n} \neq x_{n+1}$ for all $n \geq 0$. Since $T$ is $\alpha$-admissible, it is easy to check that $\alpha\left(x_{n}, x_{n+1}\right) \geq 1$ for all $n$. Let $v=d\left(T x_{0}, T^{2} x_{0}\right)+d\left(x_{0}, T x_{0}\right)$ and $\lambda=a+b$. Then $d\left(T x_{0}, T^{2} x_{0}\right) \leq v$. Now, put $x=T x_{0}$ and $y=x_{0}$. Then

$$
d\left(T^{3} x_{0}, T^{2} x_{0}\right) \leq \alpha\left(T x_{0}, x_{0}\right) d\left(T^{3} x_{0}, T^{2} x_{0}\right) \leq a d\left(T^{2} x_{0}, T x_{0}\right)+b d\left(x_{0}, T x_{0}\right) \leq \lambda \nu .
$$

By continuing this process and using a similar technique to that in the proof of Theorem 3 in [2], it is easy to see that $d\left(T^{m+1} x_{0}, T^{m} x_{0}\right) \leq 2 \lambda^{l-1} v$, where $m=2 l$ or $m=2 l-1$ for all $l \geq 2$. This implies that $d\left(T^{m+1} x_{0}, T^{m} x_{0}\right) \rightarrow 0$.

By using Lemma 2.1, $T$ has an approximate fixed point.

Also following arguments analogous to those in Theorem 3 in [2], it is easy to see that $d\left(T^{m} x_{0}, T^{n} x_{0}\right) \leq \frac{4 \lambda^{l}}{1-\lambda} v$ for all $n>m$. This shows that $\left\{x_{n}\right\}$ is a Cauchy sequence.

If $T$ is continuous and $(X, d)$ is a complete metric, then there exists $x^{*} \in X$ such that $x_{n} \rightarrow x^{*}$. Thus, $T x_{n} \rightarrow T x^{*}$ and so $T x^{*}=x^{*}$.

Now, suppose that $X$ has also the property (H). We show that $T$ has a unique fixed point.

Let $x^{*}$ and $y^{*}$ be fixed points of $T$. Choose $z \in X$ such that $\alpha\left(x^{*}, z\right) \geq 1$ and $\alpha\left(y^{*}, z\right) \geq 1$. Since $T$ is $\alpha$-admissible, $\alpha\left(x^{*}, T^{m} z\right) \geq 1$ and $\alpha\left(y^{*}, T^{m} z\right) \geq 1$ for all $m \geq 1$. Put $\lambda=a+b$ and $v=d\left(x^{*}, T^{2} z\right)+d\left(x^{*}, T z\right)$. Then we have

$$
\begin{aligned}
d\left(x^{*}, T^{3} z\right) & =d\left(T^{2} x^{*}, T^{2}(T z)\right) \leq \alpha\left(x^{*}, T z\right) d\left(T^{2} x^{*}, T^{2}(T z)\right) \\
& \leq a d\left(x^{*}, T^{2} z\right)+b d\left(x^{*}, T z\right) \leq \lambda v
\end{aligned}
$$


and

$$
\begin{aligned}
d\left(x^{*}, T^{4} z\right) & =d\left(T^{2} x^{*}, T^{2}\left(T^{2} z\right)\right) \leq \alpha\left(x^{*}, T^{2} z\right) d\left(T^{2} x^{*}, T^{2}\left(T^{2} z\right)\right) \\
& \leq a d\left(x^{*}, T^{3} z\right)+b d\left(x^{*}, T^{2} z\right)=a^{2} d\left(x^{*}, T^{2} z\right)+a b d\left(x^{*}, T z\right)+b d\left(x^{*}, T^{2} z\right) \\
& \leq a d\left(x^{*}, T^{2} z\right)+b d\left(x^{*}, T^{2} z\right)+a d\left(x^{*}, T z\right)+b d\left(x^{*}, T z\right)=\lambda v .
\end{aligned}
$$

Also, we have

$$
\begin{aligned}
d\left(x^{*}, T^{5} z\right) & =d\left(T^{2} x^{*}, T^{2}\left(T^{3} z\right)\right) \leq \alpha\left(x^{*}, T^{3} z\right) d\left(T^{2} x^{*}, T^{2}\left(T^{3} z\right)\right) \\
& \leq a d\left(x^{*}, T^{4} z\right)+b d\left(x^{*}, T^{3} z\right) \\
& \leq a^{3} d\left(x^{*}, T^{2} z\right)+a^{2} b d\left(x^{*}, T z\right)+2 a b d\left(x^{*}, T^{2} z\right)+b^{2} d\left(x^{*}, T z\right) \\
& =\left(a^{3}+2 a b\right) d\left(x^{*}, T^{2} z\right)+\left(a^{2} b+b^{2}\right) d\left(x^{*}, T z\right) \leq \lambda^{2} v
\end{aligned}
$$

and one can easily get that $d\left(x^{*}, T^{6} z\right) \leq 2 \lambda^{2} v$.

By continuing this process, we obtain $d\left(x^{*}, T^{m} z\right) \leq 2 \lambda^{l-1} v$, where $m=2 l$ or $m=2 l-1$ for all $l \geq 2$. Hence, $T^{m} z \rightarrow x^{*}$. Similarly, we can show that $T^{m} z \rightarrow y^{*}$. Thus, we get $x^{*}=y^{*}$ and so $T$ has a unique fixed point.

In 2011, Haghi, Rezapour and Shahzad proved that some fixed point generalizations are not real generalizations [9]. But the following examples show that the notion of generalized convex contractions is a real generalization for the notions of convex contractions and ordered convex contractions which were provided, respectively, in [3] and [1].

Example 3.1 Let $X=\{1,3,5\}, d(x, y)=|x-y|$ and $T$ be a selfmap on $X$ defined by $T 1=3$, $T 3=1$ and $T 5=5$. Then, by putting $a=\frac{1}{4}, b=\frac{1}{4}, x=1$ and $y=3$, we have $2=d\left(T^{2} 1, T^{2} 3\right)>$ $a d(T 1, T 3)+b d(1,3)=1$. Thus, $T$ is not a convex contraction, while by putting $\alpha(x, y)=\frac{1}{4}$ whenever $x \leq y$ and $\alpha(x, y)=0$ otherwise, $a=\frac{1}{4}$ and $b=\frac{1}{4}$, it is easy to see that $T$ is a generalized convex contraction.

Example 3.2 Let $X=\{1,3,5\}, d(x, y)=|x-y|$. Define the order $\leq$ on $X$ by $\leq=\{(1,1),(3,3)$, $(5,5),(1,3),(1,5),(3,5)\}$ and define the selfmap $T$ on $X$ by $T 1=3, T 3=1$ and $T 5=5$. Then, by putting $a=\frac{1}{4}$ and $b=\frac{1}{4}, x=1$ and $y=3$, we have

$$
2=d\left(T^{2} 1, T^{2} 3\right)>a d(T 1, T 3)+b d(1,3)=1 .
$$

If $x=3$ and $y=5$ or $x=1$ and $y=5$, then we have

$$
2=d\left(T^{2} 3, T^{2} 5\right)>a d(T 3, T 5)+b d(3,5)=1.5
$$

and

$$
4=d\left(T^{2} 1, T^{2} 5\right)>a d(T 1, T 5)+b d(1,5)=1.5 .
$$

Thus, $T$ does not satisfy the condition of Theorem 2.4 in [3]. If we put $a=\frac{1}{4}$ and $b=\frac{1}{4}$ and define $\alpha(x, y)=\frac{1}{4}$ whenever $x \leq y$ and $\alpha(x, y)=0$ otherwise, then it is easy to see that $T$ is a generalized convex contraction. 
Theorem 3.2 Let $(X, d)$ be a metric space and $T$ be a generalized convex contraction of order 2 on $X$ with the based mapping $\alpha$. Suppose that $T$ is $\alpha$-admissible and there exists $x_{0} \in X$ such that $\alpha\left(x_{0}, T x_{0}\right) \geq 1$.

Then $T$ has an approximate fixed point.

Moreover, $T$ has a fixed point whenever $T$ is continuous and $(X, d)$ is a complete metric space, and also $T$ has a unique fixed point whenever $X$ has the property $(\mathrm{H})$.

Proof Let $x_{0} \in X$ be such that $\alpha\left(x_{0}, T x_{0}\right) \geq 1$. Define the sequence $\left\{x_{n}\right\}$ by $x_{n+1}=T^{n+1} x_{0}$ for all $n \geq 0$.

If $x_{n}=x_{n+1}$ for some $n$, then we have nothing to prove.

Assume that $x_{n} \neq x_{n+1}$ for all $n \geq 0$. Since $\mathrm{T}$ is $\alpha$-admissible, it is easy to check that $\alpha\left(x_{n}, x_{n+1}\right) \geq 1$ for all $n$. Let $v=d\left(T x_{0}, T^{2} x_{0}\right)+d\left(x_{0}, T x_{0}\right), \beta=1-b_{2}$ and $\lambda=a_{1}+a_{2}+b_{1}$. Then we have

$$
\begin{aligned}
d\left(T^{3} x_{0}, T^{2} x_{0}\right) & \leq \alpha\left(T x_{0}, x_{0}\right) d\left(T^{3} x_{0}, T^{2} x_{0}\right) \\
& \leq a_{1} d\left(x_{0}, T x_{0}\right)+a_{2} d\left(T x_{0}, T^{2} x_{0}\right)+b_{1} d\left(T x_{0}, T^{2} x_{0}\right)+b_{2} d\left(T^{3} x_{0}, T^{2} x_{0}\right) \\
& \leq a_{1} v+\left(a_{2}+b_{1}\right) v+b_{2} d\left(T^{3} x_{0}, T^{2} x_{0}\right) .
\end{aligned}
$$

Hence, $d\left(T^{3} x_{0}, T^{2} x_{0}\right) \leq\left(\frac{\lambda}{\beta}\right) v$.

Now, put $x=T x_{0}$ and $y=T^{2} x_{0}$. Then

$$
\begin{aligned}
d\left(T^{3} x_{0}, T^{4} x_{0}\right) \leq & \alpha\left(T^{2} x_{0}, T x_{0}\right) d\left(T^{3} x_{0}, T^{4} x_{0}\right) \\
\leq & a_{1} d\left(T x_{0}, T^{2} x_{0}\right)+a_{2} d\left(T^{2} x_{0}, T^{3} x_{0}\right) \\
& +b_{1} d\left(T^{2} x_{0}, T^{3} x_{0}\right)+b_{2} d\left(T^{3} x_{0}, T^{4} x_{0}\right) \\
\leq & a_{1} v+\left(a_{2}+b_{1}\right) \frac{a_{1}+a_{2}+b_{1}}{1-b_{2}} v+b_{2} d\left(T^{3} x_{0}, T^{4} x_{0}\right) .
\end{aligned}
$$

Hence, $d\left(T^{3} x_{0}, T^{4} x_{0}\right) \leq\left(\frac{\lambda}{\beta}\right) v$.

Similarly, we obtain $d\left(T^{5} x_{0}, T^{4} x_{0}\right) \leq\left(\frac{\lambda}{\beta}\right)^{2} v$ and $d\left(T^{5} x_{0}, T^{6} x_{0}\right) \leq\left(\frac{\lambda}{\beta}\right)^{2} v$.

By continuing this process and following an argument similar to that in Theorem 4 in [2] (see also [1]), it is easy to see that $d\left(T^{m+1} x_{0}, T^{m} x_{0}\right) \leq\left(\frac{\lambda}{\beta}\right)^{l} v$, where $m=2 l$ or $m=2 l+1$ for $l \geq 1$ or $d\left(T^{m+1} x_{0}, T^{m} x_{0}\right) \leq\left(\frac{\lambda}{\beta}\right)^{l-1} v$, where $m=2 l$ or $m=2 l-1$ for $l \geq 2$. Thus, $d\left(T^{m+1} x_{0}, T^{m} x_{0}\right) \rightarrow 0$.

By using Lemma 2.1, $T$ has an approximate fixed point.

Now, suppose that $T$ is continuous and $(X, d)$ is a complete metric space. Then, by using a similar technique to that in the proof of Theorem 4 in [2] (see also [1]), it is easy to see that $\left\{x_{n}\right\}$ is a Cauchy sequence. Choose $x^{*} \in X$ such that $x_{n} \rightarrow x^{*}$. Since $T$ is continuous, $T x_{n} \rightarrow T x^{*}$ and so $T x^{*}=x^{*}$. If $X$ has the property $(\mathrm{H})$, then by using a similar technique to that in the proof of Theorem 3.1, we can prove uniqueness of the fixed point of $T$.

Again, the following examples show that the notion of generalized convex contractions of order 2 is a real generalization for the notions of convex contractions of order 2 and ordered convex contractions of order 2, which were provided, respectively, in [1] and [3]. 
Example 3.3 Let $X=\{1,3,5\}, d(x, y)=|x-y|$ and $T$ be a selfmap on $X$ defined by $T 1=3$, $T 3=1$ and $T 5=5$. Then, by putting $a_{1}=a_{2}=b_{1}=b_{2}=\frac{1}{8}, x=1$ and $y=3$, we have

$$
2=d\left(T^{2} 1, T^{2} 3\right)>a_{1} d(1, T 1)+a_{2} d\left(T 1, T^{2} 1\right)+b_{1} d(3, T 3)+b_{2} d\left(T 3, T^{2} 3\right)=0.8 .
$$

Thus, $T$ is not a convex contraction of order 2 , while by putting $\alpha(x, y)=\frac{1}{4}$ whenever $x \leq y$ and $\alpha(x, y)=0$ otherwise and $a_{1}=a_{2}=b_{1}=b_{2}=\frac{1}{8}$, it is easy to see that $T$ is a generalized convex contraction of order 2 .

Example 3.4 Let $X=\{1,3,5\}, \leq=\{(1,1),(3,3),(5,5),(1,3)\}, d(x, y)=|x-y|$ and $T$ be a selfmap on $X$ defined by $T 1=3, T 3=1$ and $T 5=5$. Then, by putting $a_{1}=a_{2}=b_{1}=b_{2}=\frac{1}{8}$, $x=1$ and $y=3$, we have

$$
2=d\left(T^{2} 1, T^{2} 3\right)>a_{1} d(1, T 1)+a_{2} d\left(T 1, T^{2} 1\right)+b_{1} d(3, T 3)+b_{2} d\left(T 3, T^{2} 3\right)=0.8
$$

Thus, $T$ is not an ordered convex contraction of order 2 which has been used in Theorem 2.5 of [3], while by putting $\alpha(x, y)=\frac{1}{4}$ whenever $x \leq y$ and $\alpha(x, y)=0$ otherwise and $a_{1}=a_{2}=b_{1}=b_{2}=\frac{1}{8}$, it is easy to check that the selfmap $T$ is a generalized convex contraction of order 2 .

Recently, the notion of weakly Zamfirescu mappings was provided in [19] (see also Zamfirescu [20]).

Definition 3.1 Let $(X, d)$ be a metric space and $T$ be a selfmap on $X$. Then $T$ is called weakly Zamfirescu whenever there exists $\gamma: X \times X \rightarrow[0,1]$ with

$$
\theta(a, b):=\sup \{\gamma(x, y): a \leq d(x, y) \leq b\}<1
$$

for all $0<a \leq b$, such that $d(T(x), T(y)) \leq \gamma(x, y) M_{T}(x, y)$ for all $x, y \in X$, where

$$
M_{T}(x, y)=\max \left\{d(x, y), \frac{1}{2}[d(x, T(y))+d(y, T(x))], \frac{1}{2}[d(x, T(x))+d(y, T(y))]\right\} .
$$

Now, by using the main idea of this paper, we define $\alpha$-weakly Zamfirescu selfmaps as follows.

Let $(X, d)$ be a metric space, $\alpha: X \times X \rightarrow[0, \infty)$ be a function and $T$ be a selfmap on $X$. Then $T$ is called $\alpha$-weakly Zamfirescu whenever there exists $\gamma: X \times X \rightarrow[0,1]$ with $\theta(a, b):=\sup \{\gamma(x, y): a \leq d(x, y) \leq b\}<1$ for all $0<a \leq b$ such that $\alpha(x, y) d(T(x), T(y)) \leq$ $\gamma(x, y) M_{T}(x, y)$ for all $x, y \in X$.

Theorem 3.3 Let $(X, d)$ be a metric space, $\alpha: X \times X \rightarrow[0, \infty)$ be a function and $T$ be an $\alpha$-weakly Zamfirescu selfmap on $X$. Suppose that $T$ is $\alpha$-admissible and there exists $x_{0} \in X$ such that $\alpha\left(x_{0}, T x_{0}\right) \geq 1$.

Then $T$ has an approximate fixed point.

Moreover, $T$ has a fixed point whenever $T$ is continuous and $(X, d)$ is a complete metric space. 
Proof Let $x_{0} \in X$ be such that $\alpha\left(x_{0}, T x_{0}\right) \geq 1$. Define the sequence $\left\{x_{n}\right\}$ by $x_{n+1}=T^{n+1} x_{0}$ for all $n \geq 0$. We show that $d\left(x_{n}, x_{n+1}\right) \leq \gamma\left(x_{n-1}, x_{n}\right) d\left(x_{n-1}, x_{n}\right)$ for all $n \geq 0$. Since $T$ is $\alpha$-admissible, it is easy to check that $\alpha\left(x_{n}, x_{n+1}\right) \geq 1$ for all $n$. But, for each $n$, we have

$$
\begin{aligned}
M_{T}\left(x_{n-1}, x_{n}\right)= & \max \left\{d\left(x_{n-1}, x_{n}\right), \frac{1}{2}\left[d\left(x_{n-1}, T\left(x_{n-1}\right)\right)+d\left(x_{n}, T\left(x_{n}\right)\right)\right],\right. \\
& \left.\frac{1}{2}\left[d\left(x_{n-1}, T\left(x_{n}\right)\right)+d\left(x_{n}, T\left(x_{n-1}\right)\right)\right]\right\} \\
= & \max \left\{d\left(x_{n-1}, x_{n}\right), \frac{1}{2}\left[d\left(x_{n-1}, x_{n}\right)+d\left(x_{n}, x_{n+1}\right)\right],\right. \\
& \left.\frac{1}{2}\left[d\left(x_{n-1}, x_{n+1}\right)+d\left(x_{n}, x_{n}\right)\right]\right\} \\
= & \max \left\{d\left(x_{n-1}, x_{n}\right), \frac{1}{2}\left[d\left(x_{n-1}, x_{n}\right)+d\left(x_{n}, x_{n+1}\right)\right], \frac{1}{2} d\left(x_{n-1}, x_{n+1}\right)\right\} .
\end{aligned}
$$

If $M_{T}\left(x_{n-1}, x_{n}\right)=d\left(x_{n-1}, x_{n}\right)$, then

$$
d\left(x_{n}, x_{n+1}\right) \leq \alpha\left(x_{n-1}, x_{n}\right) d\left(T\left(x_{n-1}\right), T\left(x_{n}\right)\right) \leq \gamma\left(x_{n-1}, x_{n}\right) d\left(x_{n-1}, x_{n}\right) .
$$

If $M_{T}\left(x_{n-1}, x_{n}\right)=\frac{1}{2}\left[d\left(x_{n-1}, x_{n}\right)+d\left(x_{n}, x_{n+1}\right)\right]$, then

$$
\begin{aligned}
& \alpha\left(x_{n-1}, x_{n}\right) d\left(x_{n}, x_{n+1}\right) \leq \gamma\left(x_{n-1}, x_{n}\right) \frac{\left[d\left(x_{n-1}, x_{n}\right)+d\left(x_{n}, x_{n+1}\right)\right]}{2}, \\
& d\left(x_{n}, x_{n+1}\right) \leq \frac{\gamma\left(x_{n-1}, x_{n}\right)}{2 \alpha\left(x_{n-1}, x_{n}\right)-\gamma\left(x_{n-1}, x_{n}\right)} d\left(x_{n-1}, x_{n}\right) \\
& \leq \gamma\left(x_{n-1}, x_{n}\right) d\left(x_{n-1}, x_{n}\right) .
\end{aligned}
$$

If $M_{T}\left(x_{n-1}, x_{n}\right)=\frac{1}{2} d\left(x_{n-1}, x_{n+1}\right)$, then

$$
\begin{aligned}
\alpha\left(x_{n-1}, x_{n}\right) d\left(x_{n}, x_{n+1}\right) & \leq \frac{\gamma\left(x_{n-1}, x_{n}\right)}{2} \frac{1}{2} d\left(x_{n-1}, x_{n+1}\right) \\
& \leq \frac{\gamma\left(x_{n-1}, x_{n}\right)}{2}\left[d\left(x_{n-1}, x_{n}\right)+d\left(x_{n}, x_{n+1}\right)\right],
\end{aligned}
$$

and so

$$
d\left(x_{n}, x_{n+1}\right) \leq \frac{\gamma\left(x_{n-1}, x_{n}\right)}{2 \alpha\left(x_{n-1}, x_{n}\right)-\gamma\left(x_{n-1}, x_{n}\right)} d\left(x_{n-1}, x_{n}\right) \leq \gamma\left(x_{n-1}, x_{n}\right) d\left(x_{n-1}, x_{n}\right) .
$$

Thus, the claim is proved.

This implies that the sequence $\left\{d\left(x_{n}, x_{n+1}\right)\right\}$ is non-increasing and so it converges to the real number $d=\inf _{n \geq 1} d\left(x_{n-1}, x_{n}\right)$.

We have to show that $d=0$.

Let $d>0$. Since $0<d \leq d\left(x_{n}, x_{n+1}\right) \leq d\left(x_{0}, x_{1}\right)$ for all $n, \gamma\left(x_{n-1}, x_{n}\right) \leq \theta$ for all $n$, where $\theta=\theta\left(d, d\left(x_{0}, x_{1}\right)\right)$. Hence,

$$
d \leq d\left(x_{n}, x_{n+1}\right) \leq \theta^{n} d\left(x_{0}, x_{1}\right)
$$


for all $n$. But this is impossible because $d>0$ and $0 \leq \theta<1$. Therefore, $T$ has an approximate fixed point.

Now, suppose that $(X, d)$ is a complete metric space and $T$ is continuous. Following arguments similar to those in Theorem 28 of [19], we can show that $\left\{x_{n}\right\}$ is a Cauchy sequence. This implies easily that $T$ has a fixed point.

The following examples show that there exist $\alpha$-weakly Zamfirescu mappings which are not weakly Zamfirescu.

Example 3.5 Let $X=[0,1], d(x, y)=|x-y|$, and let the selfmap $T$ on $X$ be defined by $T(x)=\frac{4}{3} x$ for all $x \in X$. Since $\gamma(0,1) \geq \frac{8}{7}$ for each existent map $\gamma$ in the definition of weakly Zamfirescu mapping, $T$ is not weakly Zamfirescu. Now, by putting $\alpha(x, y)=\frac{1}{6}$ and $\gamma(x, y)=$ $\frac{1}{2}$ for all $x, y \in X$, it is easy to check that $T$ is $\alpha$-weakly Zamfirescu.

Example 3.6 Let $X=[0, \infty), d(x, y)=|x-y|$, and let the selfmap $T$ on $X$ be defined by $T(x)=\frac{4}{3} x$ whenever $x \in[0,1]$ and $T(x)=\frac{4}{3}$ whenever $x>1$. Since $\gamma(0,1) \geq \frac{8}{7}$ for each existent map $\gamma$ in the definition of weakly Zamfirescu mappings, $T$ is not weakly Zamfirescu. Now, by putting $\alpha(x, y)=\frac{1}{50}$ and $\gamma(x, y)=\frac{1}{2}$ for all $x, y \in X$, it is easy to check that $T$ is $\alpha$-weakly Zamfirescu.

\section{Competing interests}

The authors declare that they have no competing interests.

Authors' contributions

The authors completed the paper together. All authors read and approved the final manuscript.

\section{Author details}

'Department of Mathematics, Azarbaijan University of Shahid Madani, Azarshahr, Tabriz, Iran. ${ }^{2}$ Department of Mathematics, University Politehnica of Bucharest, 313 Splaiul Independenţei, Bucharest, 060042, Romania.

\section{Acknowledgements}

Research of the first and third authors was supported by Azarbaidjan Shahid Madani University.

Received: 12 July 2013 Accepted: 16 October 2013 Published: 07 Nov 2013

\section{References}

1. Istratescu, VI: Some fixed point theorems for convex contraction mappings and mappings with convex diminishing diameters. I. Ann. Mat. Pura Appl. 130(4), 89-104 (1982)

2. Alghamdi, MA, Alnafei, SH, Radenović, S, Shahzad, N: Fixed point theorems for convex contraction mappings on cone metric spaces. Math. Comput. Model. 54, 2020-2026 (2011)

3. Ghorbanian, V, Rezapour, S, Shahzad, N: Some ordered fixed point results and the property (P). Comput. Math. Appl. 63, 1361-1368 (2012)

4. Barroso, CS, Lin, PK: On the weak-approximate fixed point property. J. Math. Anal. Appl. 365, 171-175 (2010)

5. Cabada, A, Nieto, JJ: Fixed points and approximate solutions for nonlinear operator equations. J. Comput. Appl. Math. $113,17-25(2000)$

6. Chen, $\mathrm{CM}$, Chang, TH, Huang, YH: Approximate fixed point theorems for the generalized $\Psi$-set contraction mappings on an almost $\Phi$-space. Appl. Math. Lett. 23, 152-155 (2010)

7. Kalenda, OFK: Spaces not containing $/ 1$ have weak approximate fixed point property. J. Math. Anal. Appl. 373, 134-137 (2011)

8. Kirk, WA: Remarks on approximate fixed points. Nonlinear Anal. 75(12), 4632-4636 (2011)

9. Haghi, RH, Rezapour, S, Shahzad, N: Some fixed point generalizations are not real generalizations. Nonlinear Anal. 74, 1799-1803 (2011)

10. Samet, B, Vetro, C, Vetro, P: Fixed-point theorems for $\alpha$ - $\psi$-contractive type mappings. Nonlinear Anal. 75, $2154-2165$ (2012)

11. Nawab, H, Karapınar, E, Salimi, P, Akbar, F: $\alpha$-admissible mappings and related fixed point theorems. J. Inequal. Appl. 2013, 114 (2013)

12. Alnafei, SH, Radenović, S, Shahzad, N: Fixed point theorems for mappings with convex diminishing diameters on cone metric spaces. Appl. Math. Lett. 24, 2162-2166 (2011)

13. Karapınar, E, Samet, B: Generalized $\alpha-\psi$ contractive type mappings and related fixed point theorems with applications. Abstr. Appl. Anal. 2012, 793486 (2012) 
14. Mohammadi, B, Rezapour, S, Shahzad, N: Some results on fixed points of $\alpha$ - $\psi$-Ciric generalized multifunctions. Fixed Point Theory Appl. 2013, Article ID 24 (2013)

15. Radojević, S, Paunović, L, Radenović, S: Abstract metric spaces and Hardy-Rogers-type theorems. Appl. Math. Lett. 24, 553-558 (2011)

16. Reich, S: Approximate selections, best approximations, fixed points, and invariant sets. J. Math. Anal. Appl. 62, 104-113 (1978)

17. Kohlenbach, $U$, Leustean, L: The approximate fixed point property in product spaces. Nonlinear Anal. $66,806-818$ (2007)

18. Berinde, M: Approximate fixed point theorems. Stud. Univ. Babeş-Bolyai, Math. 51(1), 11-25 (2006)

19. Ariza-Ruiza, D, Jimenez-Melado, A, Lopez-Acedo, G: A fixed point theorem for weakly Zamfirescu mappings. Nonlinear Anal. 74, 1628-1640 (2011)

20. Zamfirescu, T: Fixed point theorems in metric spaces. Arch. Math. 23, 292-298 (1972)

10.1186/1687-1812-2013-255

Cite this article as: Miandaragh et al.: Approximate fixed points of generalized convex contractions. Fixed Point Theory and Applications 2013, 2013:255

\section{Submit your manuscript to a SpringerOpen ${ }^{\circ}$ journal and benefit from:}

- Convenient online submission

- Rigorous peer review

- Immediate publication on acceptance

- Open access: articles freely available online

- High visibility within the field

- Retaining the copyright to your article 